\title{
Benefits and risks in ending regulatory exceptionalism for tobacco
}

\section{Simon Chapman}

It has often been noted that the tobacco industry is cosseted by regulatory exceptionalism. Unlike food, drink and pharmaceuticals that are taken into the body, and doctors, dentists, podiatrists, tattooists, body piercers and even brothels whose work involves various gradations of body penetration, tobacco remains the only commercial product or service intended to be taken into the body which is not commonly subject to safety regulation standards. Those wanting to do things to other's bodies have to be qualified, trained, inspected, tested and risk losing their rights to practice if breaching legislated standards. Drugs designed to save lives and enhance health are subject to elaborate regulatory controls and those selling them required to undertake degrees in pharmacy or medicine. In most nations, tobacco, which causes stratospheric death estimated to reach a billion this century, ${ }^{1}$ can be sold by anyone. Manufacturers are free to add any licit additive for whatever purpose they please.

Very few in tobacco control appear to believe this situation should continue, with most futurists now routinely calling on tobacco to be "regulated". But beyond the glib catchcry, what would regulating tobacco-the product-actually involve?

Legislated performance standards are now in place in Canada and several US states for reduced ignition propensity (RIP) cigarettes ${ }^{2}$ and have played a vanguard role in regulating tobacco. The work of the TobReg committee and its latest report ${ }^{3}$ is the first attempt in the wake of highly criticised and ultimately dangerously misleading standards based on tar levels as measures of risk ${ }^{4}$ to begin to spell out exactly how the product itself should be regulated (see page 132). TobReg's recent work is therefore a landmark in the history of tobacco control.

Correspondence to: Professor Simon Chapman, School of Public Health, Edward Ford Building A27, University of Sydney, Sydney, NSW 2006, Australia; sc@med.usyd. edu.au
The latest report has two core proposals. First, it calls for a legislated program of eventually reducing to the maximum extent technologically possible toxic substances present in cigarette smoke. Essentially, this is a recommendation driven by the precautionary principle ${ }^{5}$ that there is no sensible reason for known human carcinogens and other toxicants to be allowed to be at any higher level than the lowest levels known to be already on the market. Global differences within brands show what is currently possible and TobReg argues that maximum standards should be based on median values. Importantly here, TobReg acknowledges that "Existing science has not established that reduction of any individual toxicants in machine measured cigarette smoke. will reduce actual human exposure or disease risks... Mandating levels and removing from the market some brands with higher levels is not a statement that the remaining brands are safe or less hazardous than the brands removed...".

We will not know whether emission regulated tobacco products in fact do reduce risk until large cohorts consume them for several decades. But the corollary of rejecting the precautionary principle is to allow the absurd regulatory exceptionalism granted to tobacco to continue, thereby effectively giving carte blanche to the industry remain comfortably unaccountable to even the most basic rudiments of product safety. In the meantime, while this proposed program of regulation slowly rolls out, toxicant by toxicant, comprehensive tobacco control will continue to erode and denormalise ${ }^{6}$ smoking.

Second, TobReg recommends that "any regulatory approach [should] specifically prohibit the use of the results of the proposed testing in marketing or other communications with the consuming public including product labelling" and that "manufacturers be prohibited from making statements that a brand has met governmental regulatory standards, and from publicizing the relative ranking of brands by testing levels". The report nonetheless tacitly acknowledges that the genie will get out of the bottle because news reports typically accompany new regulatory implementation and public understanding of the changes will therefore need to be monitored.

Here the report enters decidedly treacherous waters. Tobacco industry PR machines will go into overdrive to seed news stories and commentary via independent scientists, spinning the changes in ways designed to comfort smokers and risking another major era of consumer disinformation. Indeed, many of us in tobacco control will face the daunting task of having to explain why the changes have been made if there is no evidence but only hope that they will reduce risk. Inevitably, this will be reduced to a simple and misleading message by the media that the newly regulated tobacco products are now "safer", despite the very best of intentions by TobReg that this should not happen. The almost unregulated internet in particular, with its legions of youthful participants, will be awash with misinformation.

The paradox with tobacco is that it is so dangerous, that no routine regulatory approach can make sense of it. If it was a food or drug, it would not get to first base in being allowed onto the market. The latest TobReg report takes us further than we have been before toward a regulatory scenario, but invites massive questions about both benefits and risks, particularly in the area of how the news on the development will be spun by this intrepid and ruthless industry. It invites questions too, about the extent to which many of the world's poorest nations will be able to adequately address the recommendations of the report, given the scientific sophistication and concomitant investments necessary to equip government officers with the skills to implement these and critically appraise the mountains of data that the industry will put on their desks. Some may be concerned with the extent to which attention to this aspect of tobacco control may preoccupy scarce tobacco control resources in such nations, when other vital areas remain woefully under resourced. Cooperative NorthSouth ventures in assisting with technological expertise will be critical here.

Borland $^{8}$ and Callard et al, ${ }^{9}$ have called for variations on a radical step: the de facto appropriation of the tobacco industry by governments to remove the profit motive which they correctly diagnose as being at the root of every regulatory and legislative hiatus. Liberman ${ }^{10}$ has called for more aggressive and creative prosecution 
using existing laws. The issue remains among the greatest challenges in tobacco control and TobReg has done us a great service by moving the agenda into a spotlight where it deserves prolonged debate.

\section{Competing interests: None.}

Tobacco Control 2008;17:73-74.

doi:10.1136/tc.2008.025106

\section{REFERENCES}

1. World Health Organization. WHO Report on the Global Tobacco Epidemic 2008. http://www.who.int/ tobacco/mpower/mpower report full 2008.pdf. laccessed 26 February 2008)

2. Gunja M, Wayne GF, Landman A, et al. The case for fire safe cigarettes made through industry documents. Tob Control 2002;11:346-53.

3. Burns D, Dybing E, Gray N, et al. Mandated lowering of toxicants in cigarette smoke: a description of the WHO TobReg proposal. Tob Control 2008;17:132-41.

4. Bialous SA, Yach D. Whose standard is it, anyway? How the tobacco industry determines the International Organization for Standardization (ISO) standards for tobacco and tobacco products. Tob Control 2001:10:96-104.

5. Martuzzi M, Bertollini R. The precautionary principle science and human health protection. Int J Occup Med Environ Health 2004;17:43-6.
6. Chapman S, Freeman B. Markers of the denormalisation of smoking and the tobacco industry. Tob Control 2008;17:25-31.

7. Freeman B, Chapman SLO. Tobacco promotion invades new media. Lancet Oncol 2007;8:973-4.

8. Borland R. A strategy for controlling the marketing of tobacco products: a regulated market model. Tob Control 2003;12:374-82

9. Callard C, Thompson D, Collishaw N. Transforming the tobacco market: why the supply of cigarettes should be transferred from for-profit corporations to non-profit enterprises with a public health mandate. Tob Control 2005:14:278-83.

10. Liberman $\mathbf{J}$. The future of tobacco regulation: a response to a proposal for fundamental institutional change. Tob Control 2006;15:333-8.

\section{The proposed tobacco regulation: the triumph of hope over experience?}

\section{Lynn T Kozlowski}

In tobacco control, we try to reduce death and disability from tobacco use. The job of TobReg is a tough one that its authors think someone should and can do. They may be right, but I am not yet convinced.

The industry has been faulted for its secrecy. And the absence of governmental regulation and the principles of trade secrets have supported this secrecy. Via TobReg, some of the best and the brightest in tobacco control propose extensive secrecy themselves with respect to what is learned or even thought about the toxic yields of cigarettes and possible reductions in those toxic yields. Why would those committed to improving public health want no public claims for individual products arising from systematic attempts to make cigarettes less dangerous? This could be a good idea for several reasons (in no special order): (1) the toxicant reductions may not actually produce any risk reduction to individuals; (2) the toxicant reductions may produce such small reductions in risks to individuals that they do not importantly reduce risk; or (3) the perception by smokers of reduced risks may be acted on by smokers in a way that reduces smoking cessation or promotes recruitment to smoking. Any or all of these outcomes would be seen as unfortunate for tobacco control and the TobReg effort.

Correspondence to: Lynn T Kozlowski, School of Public Health and Health Professions, University at Buffalo,

State University of New York, Buffalo, New York, USA; LK22@buffalo.edu
The many proposed controls of public knowledge or opinion on the regulatory system are "the responsibility of the regulatory structure to monitor". Really? What governmentally-budgeted thought police could truly monitor or correct the accuracy of news reports or editorials or blogs in the modern world? This proposal would take responsibility for controlling smokers' understandings and interpretations about the risks of tobacco products. And if "regulators" find consumer views are not as they wish about tobacco products or changes in tobacco products, "regulators should then pursue whatever corrective action is necessary to prevent consumers from being misled". Such power would be the unrealisable dreams of the most powerful, paternalistic totalitarian state. Do we imagine that, for example, an investigative reporter or university student somewhere in the world would not readily find the present TobReg report in Tobacco Control as an element of the public, scientific record or any of the various other published reports that will discuss and debate the TobReg proposal in the coming months or years? I believe that the "regulators" will not truly have the superpowers that are asserted-not only because of budgetary constraints, but also because the understandings and interpretations of human beings will be more often out of their reach.

Credible, organised public health efforts to make cigarettes safer will likely come to be noticed by the public, and the public will likely interpret that cigarettes as a class are becoming less dangerous. In general, the traditions of the tar and nicotine testing business around the world have tried to have it "both ways", by not officially saying that lower tar cigarettes-as a class-are safer, while permitting that inference to be drawn. In a sense, the TobReg program would allow similar inferences of reduced risk to be drawn, even though direct promotional claims of reduced risk or lower toxicant levels about specific brands would be forbidden, and even though many efforts are proposed to control the public's thoughts and understandings about tobacco products. If it ever got to legal testimony on the matter, the "regulators" themselves would be forced to acknowledge that the reductions in toxicants were intended to reduce product risks and that they may be doing just that. TobReg-type systems could contribute to the normalisation of the cigarette industry and add to the years of cigarette sales. This stateof-the-art, tobacco-control-sanctioned effort to reduce risks could cause reasonable authorities to want to see how much risks are reduced. This will take time and more research.

Once again firing up the chromatographs in the service of policy may not result in progress in tobacco control. The focus on reduced exposure cigarettes as a tool of tobacco control represents, as Samuel Johnson said of second marriages, the triumph of hope over experience. We might better consider focusing on characterising cross-product comparisons and the likely risk reduction arising from smokeless tobacco and medicinal nicotine products, placing all cigarettes squarely in the category of being too dangerous to keep tinkering with. ${ }^{1}$ Rather than hoping for secrecy and some imagined ability to repair the ill-thinking arising from any leaked information, we would be better to continue to work on how meaningful 